OPEN ACCESS

International Journal of

Environmental Research and

Public Health

ISSN 1660-4601

www.mdpi.com/journal/ijerph

Concept Paper

\title{
Effective Removal of Cadmium Ions from a Simulated Gastrointestinal Fluid by Lentinus edodes
}

Xin Qiao ${ }^{1,2}$, Wen Huang ${ }^{1,2, *}$ and Yinbing Bian ${ }^{2}$

1 College of Food Science and Technology, Huazhong Agricultural University, Wuhan 430070, China; E-Mail: qiaoxinspring@163.com

2 Institute of Applied Mycology, Huazhong Agricultural University, Wuhan 430070, China; E-Mail: bianyb.123@163.com

* Author to whom correspondence should be addressed; E-Mail: huangwen@mail.hzau.edu.cn.

External Editor: Paul B. Tchounwou

Received: 12 October 2014; in revised form: 24 November 2014 / Accepted: 25 November 2014 / Published: 1 December 2014

\begin{abstract}
Lentinus edodes, a functional food, was evaluated as a potential antidote for adsorption/removal of cadmium ion from simulated gastrointestinal fluids. An adsorption/removal capacity of $65.12 \mathrm{mg} / \mathrm{g}$ was achieved by L. edodes in solutions with a $\mathrm{pH}$ ranging from 2.5 to 6.0 , while little if any adsorption was observed in solutions with a $\mathrm{pH}$ under 2.5. In solutions with $\mathrm{pH} 6.0,84 \%$ of the cadmium adsorption by $L$. edodes occurred in the first minute. Scanning electronic microscopic examination showed that the cell wall polysaccharides of $L$. edodes provided a rough sponge-like surface for effective cadmium adsorption. FTIR indicated that the carboxyl, hydroxyl and $-\mathrm{NH}$ groups of the cell wall polysaccharides and proteins were the primary functional groups that chemically bind with cadmium ions. The energy dispersive spectrometry further revealed that cation exchange might be attributed to cadmium biosorption. These results suggested that L. edodes was effective for cadmium detoxication, especially in low concentration.
\end{abstract}

Keywords: adsorption; antidote; cadmium; heavy metal; L. edodes; simulated gastrointestinal fluid 

Abbreviations
L. edodes: Lentinus edodes
FTIR: $\quad$ Fourier transform infrared analysis
DMSA: dimercaptosuccinic acid
DMPS: dimercaptopropanesulfonate
EDTA: ethylenediaminetetraacetic acid
EDS: energy dispersive spectrometry
GFAAS: $\quad$ atomic absorption spectrometry
SEM: scanning electron microscope

\section{Introduction}

Cadmium pollution has become a serious issue in recent years [1]. Uptake of this toxic compound can result in multiple human health problems such as lung insufficiency, cardiovascular system disturbances, liver and kidney damage and cancer [2-4]. How to prevent and/or minimize its damage in case of uptake is becoming a worldwide research interest. Application of complex chelating agents is the current approach to treat cadmium poisoning. For example, British anti-Lewisite, dimercapto-succinic acid (DMSA), dimercaptopropanesulfonate (DMPS) and ethylenediaminetetraacetic acid (EDTA) are used to treat patients suffering from heavy metal intoxication [5-9]. Upon administration, these chelating complexes bind with heavy metals such as cadmium, that will be removed eventually through the kidney. However, this approach requires multiple administrations which may cause a burden to and damage the renal system during the clearance of metal chelates from the body. In addition, these chelating agents are capable of binding essential metals, resulting in severe mineral deficiency and anemia $[8,10,11]$. Therefore, it is imperative to develop an effective and safe detoxification agent for the treatment of cadmium intoxication.

L. edodes has been recognized as a healthy food. It is rich in nutrients, with a unique flavor, and it contains a variety of physiological active substances. More importantly, its capacity for adsorbing heavy metals is much higher than that of green plants and animal-derived food [12,13]. For the above-mentioned reasons, it was of interest to evaluate $L$. edodes as a potential chelating agent for the therapeutic treatment of cadmium poison without significant side effects. To this end, we have characterized the capacity of the L. edodes for adsorption/removal of cadmium from simulated gastrointestinal fluids.

\section{Materials and Methods}

\subsection{Preparation of L. edodes Powder and Cadmium Solution}

L. edodes (L26) was collected from the Institute of Applied Mycology, Huazhong Agricultural University, Wuhan, China. The collected samples were washed multiple times using sterile physiological saline, oven-dried at $80^{\circ} \mathrm{C}$ for $24 \mathrm{~h}$, and grounded using a roll crusher. The grounded L. edodes powder with a certain size were obtained through a plastic sieve, and stored for use as antidote. 
A stock solution $(1000 \mathrm{mg} / \mathrm{L})$ of $\mathrm{Cd}(\mathrm{II})$ was prepared by dissolving $\mathrm{CdCl}_{2}$ (analytical grade) in deionized water. The stock solution was diluted as needed for specific experiments.

\subsection{Effect of $p H$ on Adsorption}

A solution containing $100 \mathrm{mg} / \mathrm{L}$ cadmium was made from the stock solution, and then divided into seven equal volumes $(500 \mathrm{~mL})$. The $\mathrm{pH}$ of these seven solutions was adjusted to 2.5, 3, 4, 5, 6, 7 and 8 , respectively, using $1 \mathrm{M} \mathrm{HCl}$ or $\mathrm{NaOH}$. Each solution was mixed with $L$. edodes powder $(<100 \mu \mathrm{m}$; $1 \mathrm{~g} / \mathrm{L})$, incubated for $2 \mathrm{~h}\left(140 \mathrm{rpm}, 37^{\circ} \mathrm{C}\right)$. After centrifugation, the supernatant was analyzed for the remaining cadmium.

\subsection{Effect of Powder Size}

Three diluted cadmium solutions (50, 100 and $200 \mathrm{mg} / \mathrm{L})$ were prepared from the stock solution. After $\mathrm{pH}$ adjustment (6.0), each diluted solutions were divided into 13 equal volumes $(500 \mathrm{~mL})$. Three sets of antidote were weighted; with each set containing 4 samples with different size of $L$. edodes powder $(<100,100-125,125-150,150-180$ and 180-210 $\mu \mathrm{m} ; 1 \mathrm{~g} / \mathrm{L})$. These antidotes were then added into the corresponding cadmium solution (39 samples). These samples were then incubated for $2 \mathrm{~h}$ $\left(140 \mathrm{rpm}, 37^{\circ} \mathrm{C}\right)$. After centrifugation, the supernatant was analyzed for the remaining cadmium.

\subsection{Effect of Initial Cadmium Ion Concentration}

A series of solutions were prepared, with each containing 5, 10, 20, 50, 100, 200, 300, 400, 500, $600 \mathrm{mg} / \mathrm{L}$ cadmium, respectively. After $\mathrm{pH}$ adjustment (6.0), these solutions were mixed with the L. edodes antidote $(<100 \mu \mathrm{m} ; 1 \mathrm{~g} / \mathrm{L})$. The mixture was incubated for $2 \mathrm{~h}\left(140 \mathrm{rpm}, 37^{\circ} \mathrm{C}\right)$. These samples were then centrifuged; and the supernatant was analyzed for the remaining cadmium.

\subsection{Cadmium Adsorption Time Course}

Three cadmium solutions (50, 100 and $200 \mathrm{mg} / \mathrm{L}$ ) was made from the stock solution, and then adjusted the $\mathrm{pH}$ to 6.0. These solutions were then mixed with the $L$. edodes antidote $(<100 \mu \mathrm{m} ; 1 \mathrm{~g} / \mathrm{L})$. These mixtures were incubated at $37^{\circ} \mathrm{C}(140 \mathrm{rpm})$. Samples were taken after $0.5,1,2,3,5,8,12,16$, $20,30,60$, and $120 \mathrm{~min}$ incubation, and were filtered. The supernatant were analyzed to determine the remaining cadmium concentration. All experiments were done in triplicate.

\subsection{Simulated Intestinal Fluids Treatment}

The simulated intestinal fluids were prepared according to the USP guide by mixing in order the following components: monobasic potassium phosphate $(6.8 \mathrm{~g})$ dissolved in water $(250 \mathrm{~mL}), 0.2 \mathrm{M}$ sodium hydroxide $(77 \mathrm{~mL})$, water $(500 \mathrm{~mL})$, and pancreatin $(10.0 \mathrm{~g}$, obtained from porcine pancreas). The mixture was adjusted to $\mathrm{pH} 6.8 \pm 0.1$ with either $0.2 \mathrm{M}$ sodium hydroxide or $0.2 \mathrm{M}$ hydrochloric acid and then diluted with water to the final volume of $1000 \mathrm{~mL}$. The simulated intestinal fluids were divided into a series of $100 \mathrm{~mL}$ solution. The cadmium ion was added to the $100 \mathrm{~mL}$ simulated intestinal fluids at 1, 5, 100, $200 \mathrm{mg} / \mathrm{L}$ respectively. The $L$. edodes powder $(<100 \mu \mathrm{m} ; 1 \mathrm{~g} / \mathrm{L})$ were then 
added to the cadmium containing fluids, and incubated for $2 \mathrm{~h}\left(140 \mathrm{rpm}, 37^{\circ} \mathrm{C}\right)$. After centrifugation, the supernatant was analyzed for the remaining cadmium.

\subsection{Analysis}

The cadmium concentration was determined using a graphitefurnaceatomicabsorption spectrometry (GFAAS, AA6300, Shimadzu, Kyoto, Japan). The cadmium adsorbed on antidote was calculated from the initial and the remaining cadmium concentration after adsorption. The surface morphology of the antidote powder was examined by scanning electronmicroscope (SEM, JSM-5610LV, JEOL, Kyoto, Japan) with $5000 \times$ magnification and an accelerating voltage of $25 \mathrm{keV}$. Elemental compositions before and after adsorption were determined by the energy dispersive spectrometry (EDS, JEM, Kyoto, Japan) with $200 \mathrm{KV}$ accelerating voltage. The chemical property of the antidote surface was characterized using Fourier transform infrared (FTIR) analysis (Nicolet 5700 Thermo, MA, USA). A mass ratio of the sample to $\mathrm{KBr}$ at 1:100 was used for the preparation of the disks, and the spectral range of $4000 \mathrm{~cm}^{-1}$ to $400 \mathrm{~cm}^{-1}$ was used for FTIR analysis.

\section{Results and Discussion}

\subsection{Weak Acidic pH Favored Cadmium Adsorption/Removal}

The $\mathrm{pH}$ level may affect the functional groups (hydroxyl, carboxylate and amino groups) of the antidote, the stability of metal complex [1,14], and eventually the effectiveness of the antidote for detoxification of heavy metal poison. Indeed, the antidote will encounter a wide range of $\mathrm{pH}$ environment when administered to humans, as the human gastrointestinal $\mathrm{pH}$ varies from strong acid to weak base ( $\mathrm{pH} 2-8)[11,15,16]$. To this end, the $\mathrm{pH}$ effect was evaluated for cadmium adsorption by L. edodes powder (Figure 1).

Figure 1. Effect of $\mathrm{pH}$ on cadmium binding. Conditions: Initial cadmium, $100 \mathrm{mg} / \mathrm{L}$; antidote dose, $1 \mathrm{~g} / \mathrm{L}$; temperature, $37^{\circ} \mathrm{C}$; incubation time, $2 \mathrm{~h}$.

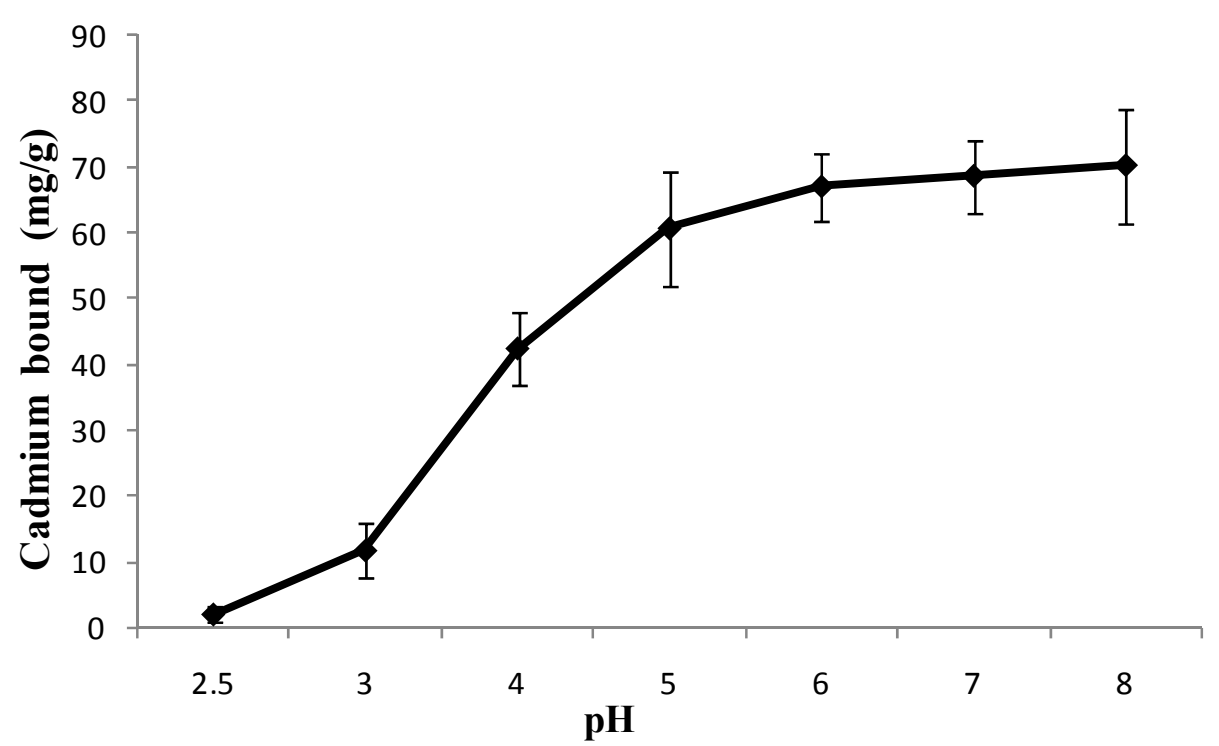

Notes: The statistical significance between cadmium bound and $\mathrm{pH}$ was remarkable difference $(p<0.05)$. 
Little if any cadmium adsorptions were observed when the $\mathrm{pH}$ was less than 2.5; the cadmium adsorption increased from 0 to $65.12 \mathrm{mg} / \mathrm{g}$ when the $\mathrm{pH}$ increased from 2.5 to 6.0 ; while no further increase of adsorption (reached to plateau) when the $\mathrm{pH}$ further increased from 6.0 to 8.0. These results suggested that weak acid conditions favor effective cadmium adsorption by $L$. edodes.

This little or no cadmium adsorption under $\mathrm{pH} 2.5$ may be attributed to the effective competition of hydrogen ions (proton) for the available binding sites of $L$. edodes powder. When the $\mathrm{pH}$ increased from 2.5 to 6.0, however, the weak acid conditions provided favorable conditions for the ionization of cadmium $\left(\mathrm{Cd}^{2+}\right)$ that could readily bind with the negative charged binding sites of L. edodes antidote [17]. Due to its low $\mathrm{pH}(<2.5)$ and a relatively short food retention, the stomach seems to not be a significant organ for cadmium adsorption by L. edodes. On the contrary, the small intestine has a weakly acidic environment and a long food retention period, providing a primary organ for detoxification of cadmium by L. dodes antidote.

\subsection{Smaller Antidote Powder Size Improved Cadmium Removal}

The surface contact of antidote plays an important role for bioadsorption. The effect of different antidote powder size $(<100,100-125,125-150,150-180,180-210 \mu \mathrm{m})$ on cadmium adsorption/removal was investigated using three different initial cadmium concentrations (Figure 2).

Figure 2.Effect of antidote powder size on cadmium adsorption. Conditions: 50, 100 and $200 \mathrm{mg} / \mathrm{L}$; $\mathrm{pH}, 6$; antidote dose, $1 \mathrm{~g} / \mathrm{L}$; temperature, $37^{\circ} \mathrm{C}$; incubation time, $2 \mathrm{~h}$.

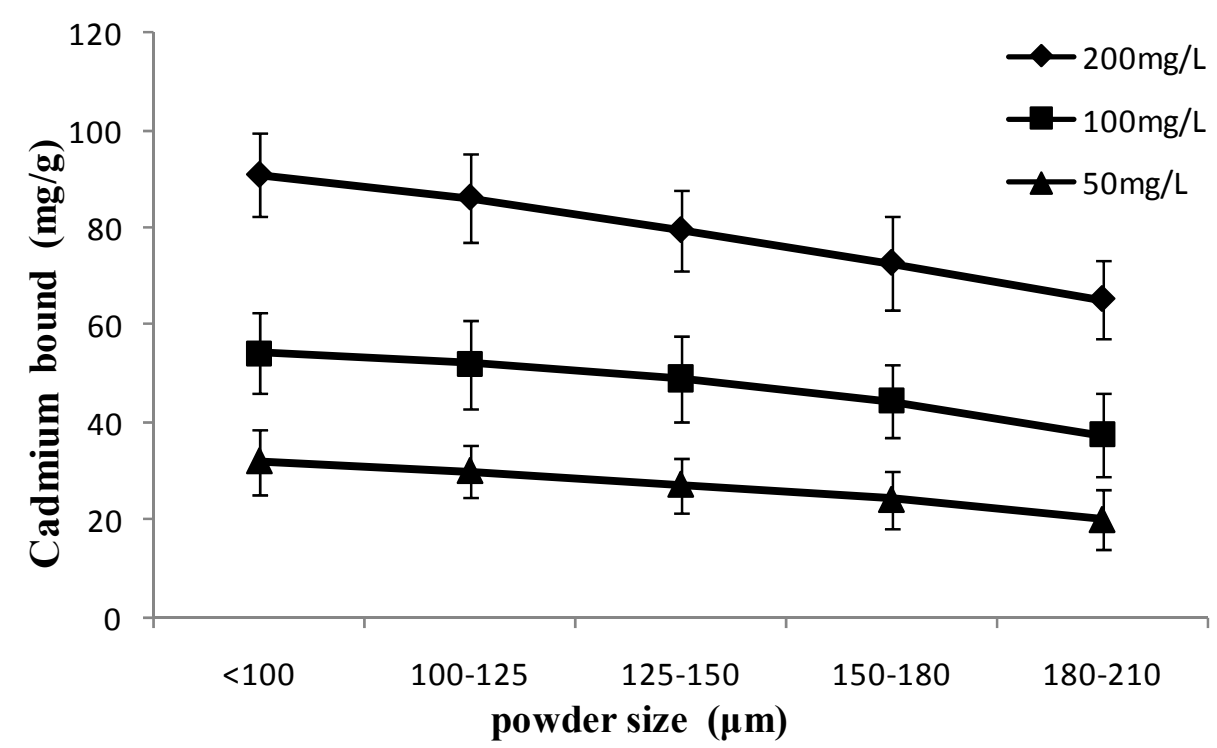

Notes: The statistical significance between cadmium bound and powder size in all three concentrations was significant $(p<0.01)$.

At $100 \mathrm{mg} / \mathrm{L}$ initial cadmium, the amount of cadmium bound to the antidote decreased from $54.28 \mathrm{mg} / \mathrm{g}$ to $37.45 \mathrm{mg} / \mathrm{g}$ as the powder size increase from less than $100 \mu \mathrm{m}$ to $180-210 \mu \mathrm{m}$. The adsorption data in Figure 2 showed that cadmium adsorbed/removed was approximately negative linear relation with the antidote powder size. It is believed that smaller powder size might enhance specific surface area, favoring the effective interaction between the antidote particles and cadmium ions [18]. Additionally, a similar relationship was observed between the antidote powder size, the adsorption/removal of cadmium, 
and the binding capacity per unit of antidote when the initial cadmium concentration was 50 and/or $200 \mathrm{mg} / \mathrm{L}$.

\subsection{Initial Cadmium Concentration Affected Effective Adsorption/Removal}

A series of solutions with different initial cadmium concentrations ( 5 to $600 \mathrm{mg} / \mathrm{L}$ ) were used to evaluate the effect of initial cadmium concentration on effective adsorption/removal by L. edodes (Figure 3). At the initial cadmium concentration of 5-20 mg/L, a low specific binding (less than $10 \mathrm{mg} / \mathrm{g}$ ) of $L$. edodes was observed. However, when the initial cadmium concentration was in the range of 20-400 $\mathrm{mg} / \mathrm{L}$, the specific cadmium adsorption of $L$. edodes increased rapidly, forming an approximately linear curve. To the higher end of initial cadmium concentration of $400-600 \mathrm{mg} / \mathrm{L}$, the uptake speed decreased gradually. This phenomenon could be that an increase in the amount of cadmium ions caused competition for the available binding sites on the surface of antidote $[16,19]$. At higher concentration, the cadmium ion density was enhanced on the antidote surface, which promoted the integration between cadmium and the binding sites. In other words, high cadmium concentration plays a key role in overcoming of the mass transfer resistance between the aqueous and solid phases $[15,20]$.

Figure 3. Effect of the initial cadmium concentration on adsorption. Conditions: $\mathrm{pH}, 6$; antidote dose, $1 \mathrm{~g} / \mathrm{L}$; temperature, $37^{\circ} \mathrm{C}$; incubation time, $2 \mathrm{~h}$.

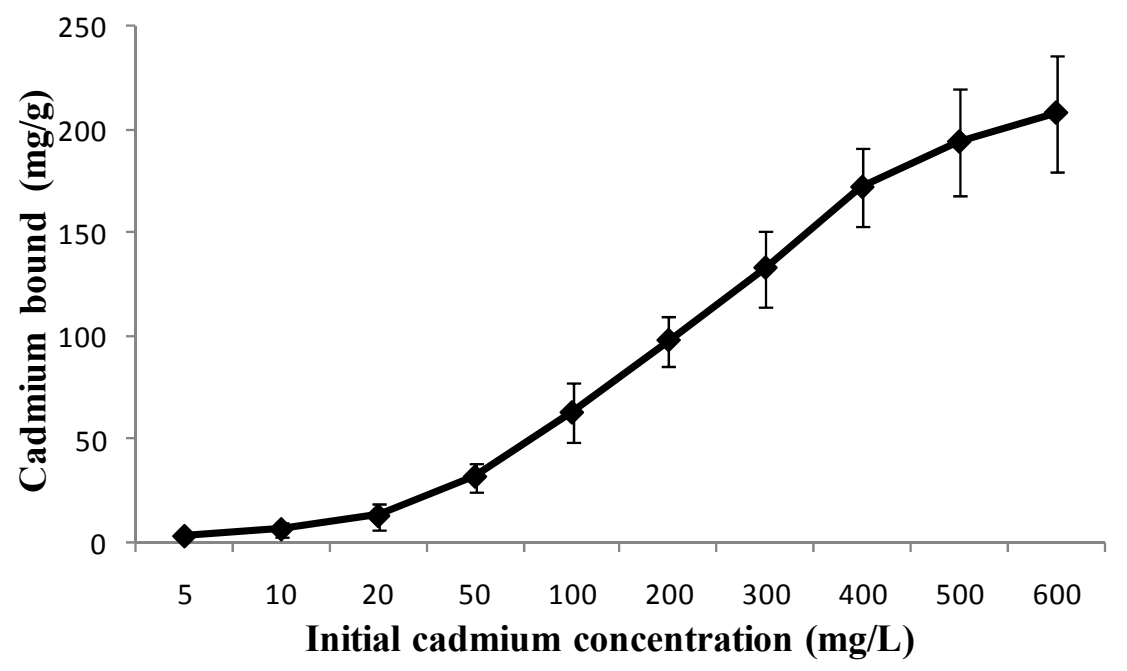

Notes: The statistical significance between cadmium bound and initial cadmium concentration was significant $(p<0.01)$.

\subsection{Cadmium Ion Binds to L. edodes Rapidly}

The adsorption rate is an important parameter for an antidote to detoxify cadmium. To evaluate the potential of $L$. edodes to serve as an antidote for cadmium intoxication, three different initial cadmium concentrations $(50,100,200 \mathrm{mg} / \mathrm{L})$ were used to study the contact time requirement of $L$. edodes for efficient cadmium removal (Figure 4). The cadmium adsorption by L. edodes took place rapidly. Specifically, 19.77, 48.33 and $69.72 \mathrm{mg}$ cadmium was adsorbed by L. edodes in just one minute for the solutions containing 50,100, and $200 \mathrm{mg} / \mathrm{L}$ initial cadmium, respectively. In fact, the first minute's 
adsorption accounted for $84 \%$ of the total adsorbed cadmium. Further increase contact time had an inconspicuous effect on cadmium adsorption. The slow adsorption after one minute may be attributed to the transfer resistance of cadmium ion to the antidote particles [21]. Nevertheless, this rapid adsorption behavior of $L$. edodes is a positive indication for its usefulness in the treatment of acute cadmium intoxication.

Figure 4. Effect of contact time on cadmium adsorption. Conditions: initial cadmium concentrations: 50, 100 and $200 \mathrm{mg} / \mathrm{L}$ for; $\mathrm{pH}, 6$; antidote dose, $1 \mathrm{~g} / \mathrm{L}$; temperature, $37^{\circ} \mathrm{C}$; incubation time, $2 \mathrm{~h}$.

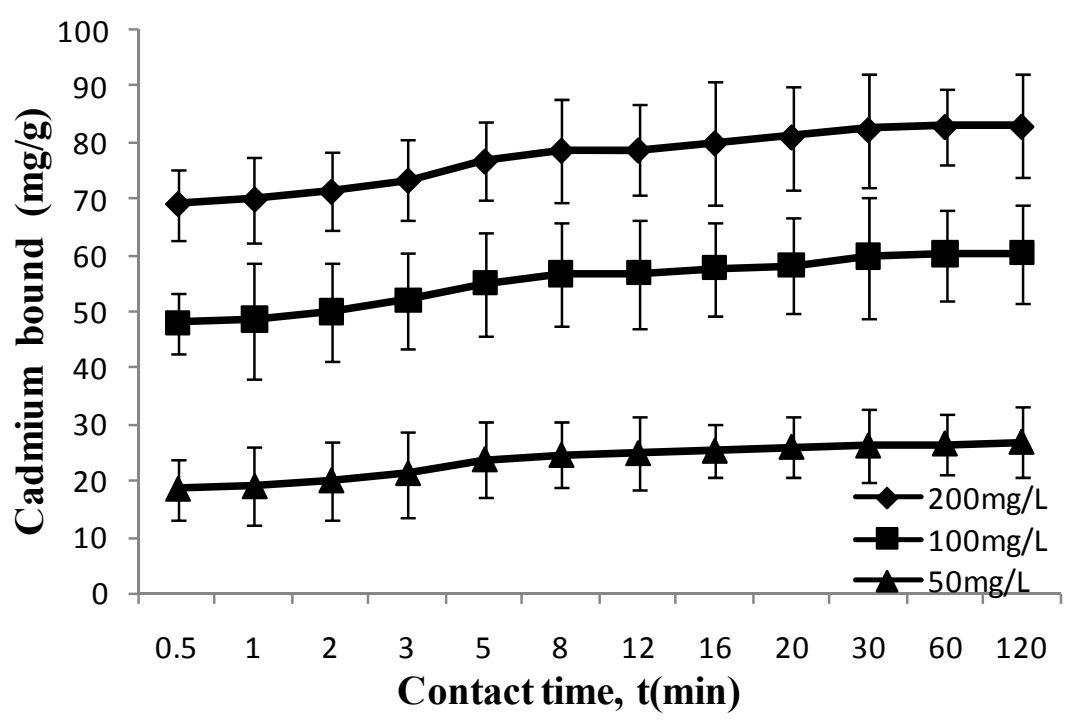

Notes: The statistical significance between cadmium bound and contact time at all three concentrations was remarkable $(p<0.05)$.

\subsection{Hydroxyl, Carboxyl and-NH Groups of Polysaccharides and Proteins Provide the Sites for Cadmium Binding}

As shown in Figure 5, there was a significant change of the fruiting body surface of $L$. edodes when bound to cadmium ions. Before binding (Figure 5a), the surface was rough and sponge-like. These surface properties could provide large specific surface area, reduce the diffusion resistance and facilitate mass transfer, contributing to the adsorption process. The surface of the cadmium-loaded L. edodes (Figure 5b) was smooth. Chemical interactions between the functional groups of the L. edodes and cadmium ions might be responsible for the observed surface structure changes.

To understand the chemical interactions of L. edodes and cadmium ion, a Fourier transform infrared analysis was used to obtain functional group information about the L. edodes surface, with the assumption that the energy absorption bands should be different before and after cadmium adsorption [12]. The primary components of L. edodes are polysaccharides (pectin, cellulose, hemicellulose and chitin), which comprise a large amount of hydroxyl groups that can be reflected by the strong and wide absorption peak at $3400 \mathrm{~cm}^{-1}$. As demonstrated in Figure 6, the hydroxyl absorption peak around $3394 \mathrm{~cm}^{-1}$ shifted to $3426 \mathrm{~cm}^{-1}$ after cadmium absorption, indicating that the hydroxyl groups had been changed from multimer to monopolymer or even a dissociative state [22]. In addition, the characteristic absorption peak at $1638 \mathrm{~cm}^{-1}$ indicated the presence of the carboxyl groups of the pectin 
component. The new absorption peak appeared at 955-915 $\mathrm{cm}^{-1}$ after cadmium absorption might be due to the structural changes caused by carboxyl vibrations [23]. Furthermore, a new peak observed at about $1547 \mathrm{~cm}^{-1}$ indicated that there was an amide group-NH stretching, which suggested that proteins of L. edodes were also involved in the cadmium bonding reaction [24]. These results indicated that the polysaccharides and proteins present on the surface of $L$. edodes provide the opportunity to bind cadmium ions through chemical interactions.

Figure 5. Surface morphology of L. edodes. (a) before cadmium adsorption; (b) after cadmium adsorption.

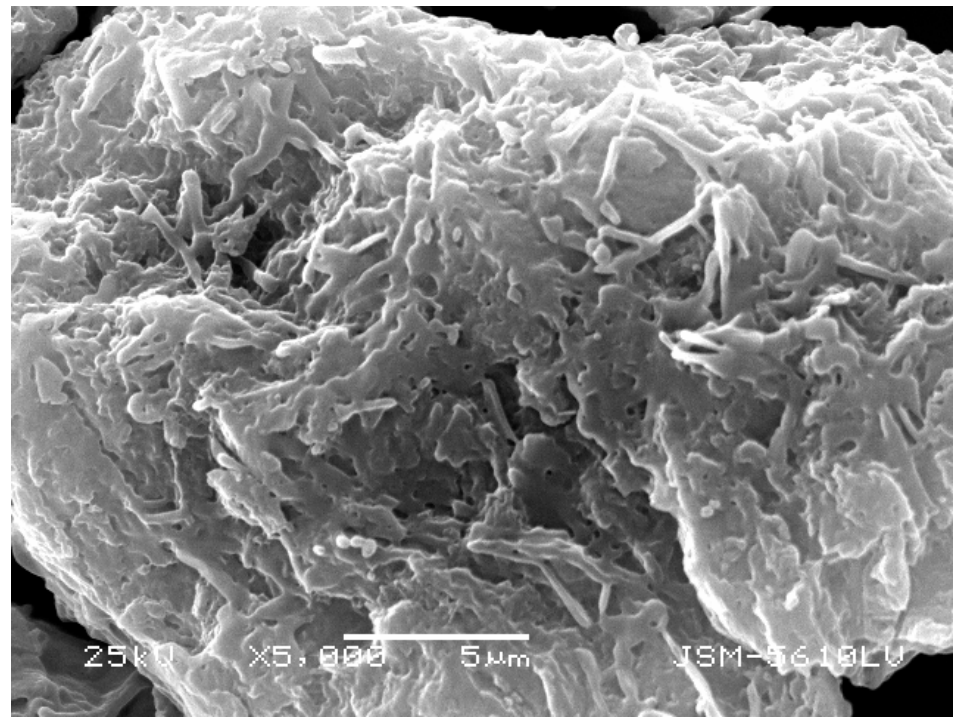

(a)

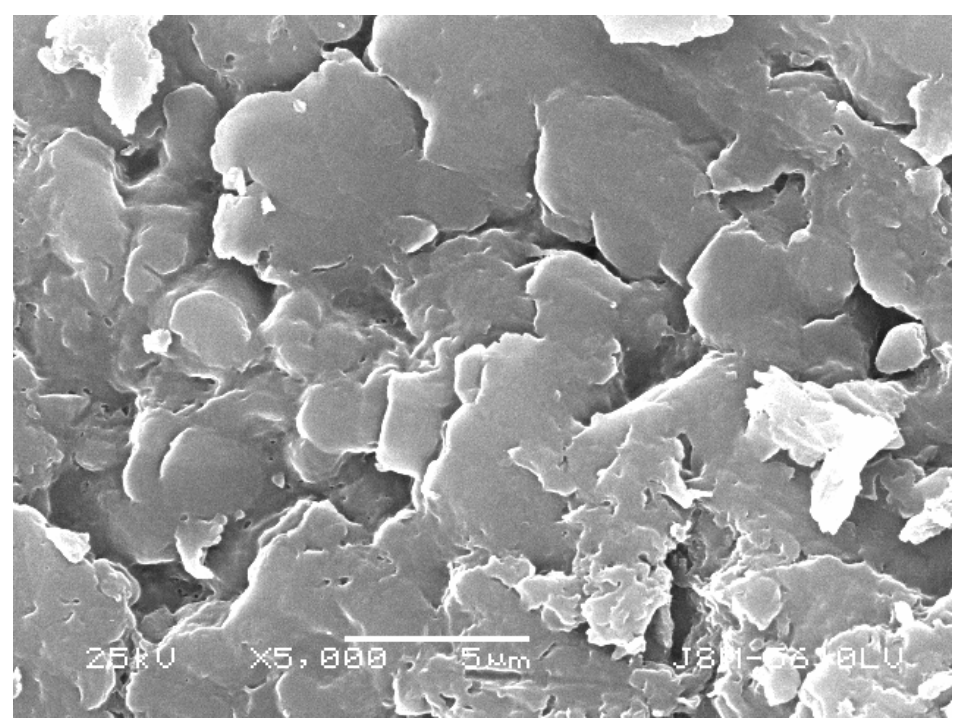

(b)

The energy dispersive spectrometries of $L$. edodes powder before and after adsorption are shown in Figure 7, which indicated that carbon and oxygen are the predominant elements of the antidote. It is clearly seen that potassium and calcium peaks were not detected and a new cadmium peak appeared after biosorption. Thus, there was a possible cation exchange in the cadmium biosorption process, which had been reported by Davis [25]. 
Figure 6. Fourier transform infrared (FTIR) spectrum of L. edodes. Bottom black line, L. edodes surface; Top red line, Cd-loaded L. edodes surface.

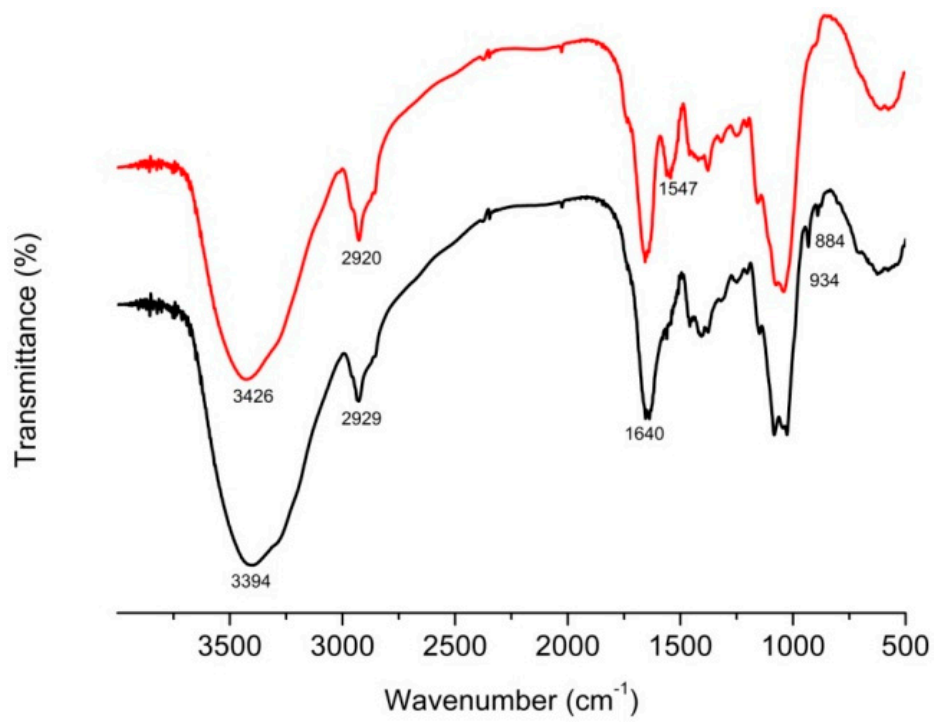

Figure 7. EDS spectrums of L. edodes. (a) before cadmium adsorption; (b) after cadmium adsorption.

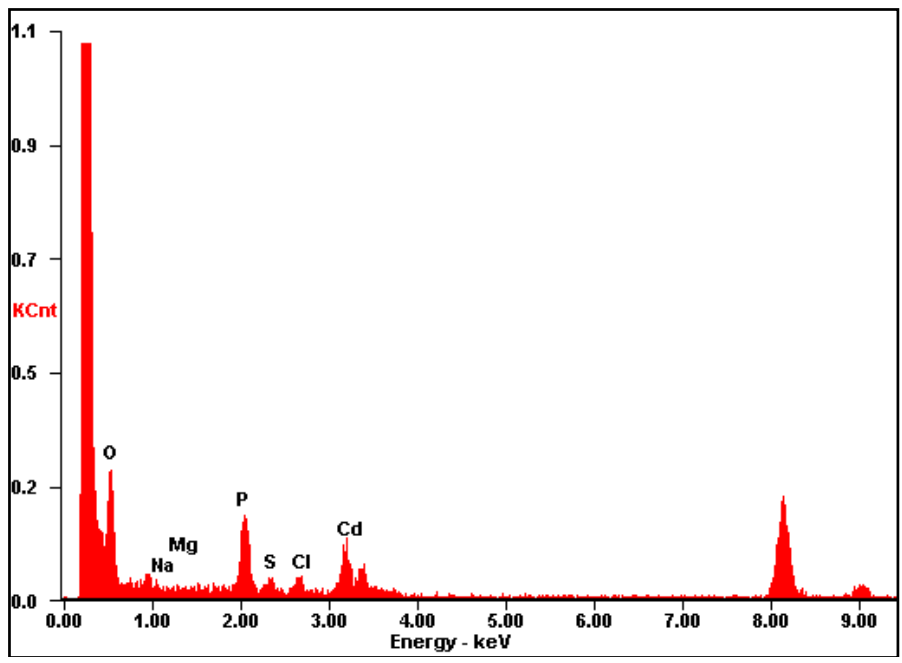

(a)

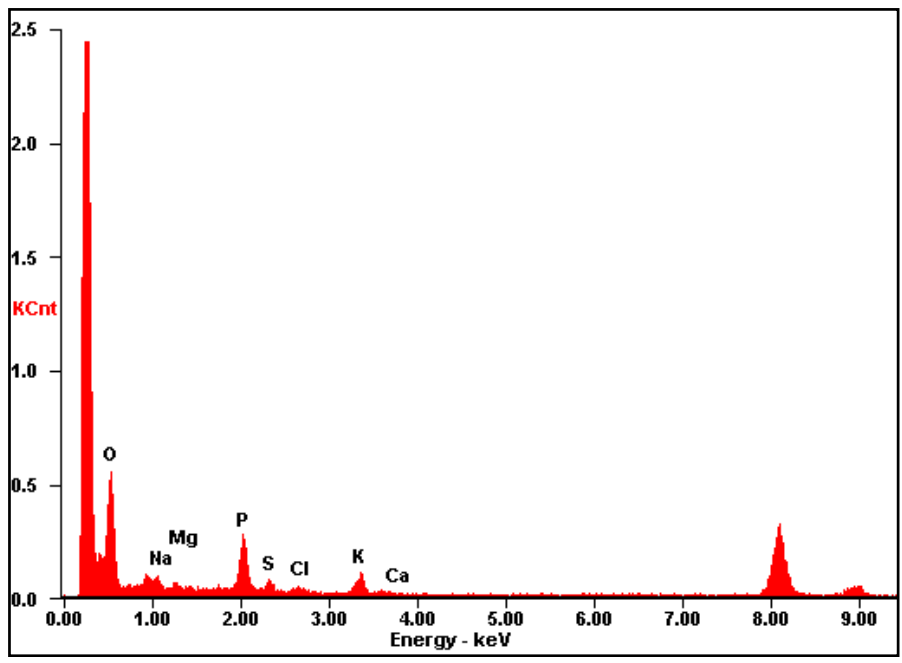

(b) 


\subsection{Cadmium Adsorption Fitted well with the Languir and Freundlich Models}

In order to predict the adsorption behavior of the antidote, it is necessary to establish an appropriate mathematical model to optimize the adsorption process for efficient cadmium removal. Toward this goal, the following commonly used Langmuir and Freundlich models [26] were used to evaluate cadmium adsorption process:

$$
\frac{C_{e}}{q_{e}}=\frac{1}{q_{\max } K_{L}}+\frac{1}{q_{\max }} C_{e} \lg q_{e}=\lg \mathrm{K}_{\mathrm{F}}+\frac{1}{n} \lg C_{e}
$$

where $C_{e}$ is the equilibrium concentration of cadmium ion $(\mathrm{mg} / \mathrm{L}) ; q_{e}$ is the amount of cadmium ion adsorbed at equilibrium $(\mathrm{mg} / \mathrm{g}) ; q_{\max }$ is the maximum amount of cadmium ion per unit mass of adsorbent $(\mathrm{mg} / \mathrm{g}) ; K_{L}(\mathrm{~L} / \mathrm{mg})$ is the Langmuir absorptionconstant representing energy of absorption; $K_{F}$ and $\mathrm{n}$ are the Freundlich equilibrium constants indicative of adsorption capacity (mg/g) and adsorption intensity $(\mathrm{g} / \mathrm{L})$.

The related parameters of Langmuir and Freundlich model for cadmium adsorption were shown Table 1. The cadmium adsorption fitted well with both models, with their simulated linear correlation coefficients were greater than 0.97. Moreover, the correlation coefficient of Freundlich model fitted better than that of Langmuir model. The maximum uptake $\mathrm{q}_{\max }$ of cadmium was $333.33 \mathrm{mg} / \mathrm{g}$ at $\mathrm{pH} 6$. The antidote $\mathrm{q}_{\max }$ value was higher than that reported for cadmium binding in vitro by therapeutic drugs such as penicillamine, activated carbon, or sodium thiosulfate, which display absorption capacities of $3.2,4.0,328.8 \mathrm{mg} / \mathrm{g}$, respectively. In addition, the adsorption intensity $\mathrm{n}$ calculated by the Freundlich equation was 1.308 , which lies in the 1-10 range, suggesting a favorable binding by L. edodes [27]. Therefore, the relatively low-cost and high cadmium adsorption affinity of L. edodes make it an attractive potential antidote for the removal of cadmium from theintestine.

Table1.Biosorption equilibrium parameters obtained from Langmuir and Freundlich isotherms.

\begin{tabular}{cccc}
\hline Model Parameters & Langmuir & Model Parameters & Freundlich \\
\hline $\mathrm{q}_{\max }(\mathrm{mg} / \mathrm{g})$ & 333.33 & $\mathrm{n}(\mathrm{g} / \mathrm{L})$ & 1.308 \\
$\mathrm{~K}_{\mathrm{L}}(\mathrm{L} / \mathrm{mg})$ & 0.002 & $\mathrm{~K}_{\mathrm{F}}(\mathrm{mg} / \mathrm{g})$ & 2.72 \\
$\mathrm{R}^{2}$ & 0.978 & $\mathrm{R}^{2}$ & 0.981 \\
\hline
\end{tabular}

Notes: $\mathrm{q}_{\max }$ : maximum amount of cadmium ion per unit mass of adsorbent;

$\mathrm{K}_{\mathrm{L}}$ : absorption energy; $\mathrm{R}^{2}$ : linear correlation coefficients; $\mathrm{n}$ : adsorption intensity;

$\mathrm{K}_{\mathrm{F}}$ : adsorption capacity.

\subsection{Effective Detoxication of Simulated "Cadmium Contaminated” Intestinal Fluids}

The effect of $L$. edodes $(1 \mathrm{mg} / \mathrm{L})$ on cadmium removal from the simulated intestinal fluids was evaluated using four different initial cadmium concentrations (Table 2). After treatment with the antidote powder, the cadmium ion concentrations in the simulated intestinal fluids decreased by at least $50 \%$. Specifically, $50.8 \%, 61.73 \%, 68.6 \%$ and $80 \%$ cadmium were removed from the simulated intestinal fluids with the initial cadmium concentration of $200 \mathrm{mg} / \mathrm{L}, 100 \mathrm{mg} / \mathrm{L}, 5 \mathrm{mg} / \mathrm{L}$ and $1 \mathrm{mg} / \mathrm{L}$, respectively. These results suggested that the antidote powder was effective in cadmium detoxication, especially in low concentration. 
Table 2. Evaluation of cadmium removal in the simulated intestinal fluids.

\begin{tabular}{lcccc}
\hline Before Treatment (Cadmium, mg/L) & $\mathbf{1}$ & $\mathbf{5}$ & $\mathbf{1 0 0}$ & $\mathbf{2 0 0}$ \\
\hline After treatment (cadmium, mg/L) & 0.2 & 1.57 & 39.27 & 98.33 \\
Removal efficiency (\%) & 80 & 68.6 & 61.73 & 50.8 \\
\hline
\end{tabular}

\section{Conclusions}

As an antidote, L. edodes powder effectively removed cadmium ions in vitro from a simulated gastrointestinal fluid with a $\mathrm{pH}$ of $6.8( \pm 0.1)$. A first minute removal capacity of $19.77,48.33$ and $69.72 \mathrm{mg}$ was observed for initial cadmium concentrations of $50,100,200 \mathrm{mg} / \mathrm{L}$, respectively. The amount of cadmium bound to the antidote, however, decreased from $54.28 \mathrm{mg} / \mathrm{g}$ to $37.45 \mathrm{mg} / \mathrm{g}$ when the powder size increased from $<100$ to $180-210 \mu \mathrm{m}$ when the initial cadmium concentration was $100 \mathrm{mg} / \mathrm{L}$. The rough and sponge-like surface of $L$. edodes observed by scanning electron microscopy was more conducive to the adsorption process. FTIR analysis showed that the functional groups from the polysaccharides and proteins of $L$. edodes, such as hydroxyl, carboxyl and -NH groups, provided the necessary sites to bind cadmium ions through chemical interactions, including cation exchange, as observed from the EDS spectra. Our results from the simulated intestinal fluids study showed that L. edodes was effective for cadmium detoxication, especially at low concentration. These findings are considered to be therapeutically beneficial for clinical treatment of cadmium intoxication.

\section{Acknowledgements}

The authors are grateful for the financial support from the National Natural Science Foundation of China (No. 31071499) and the Science and Technology Support Program of Hubei Province (No.2013BBB06).

\section{Author Contributions}

Wen Huang provided the original concept for the study, with all co-authors involving the experimental design. Yinbing Bian was responsible for recruitment and follow-up of the study participants. Xin Qiao was responsible for carrying out the experiment, data analysis and drafting the manuscript, which was read, revised and approved by all co-authors.

\section{Conflicts of Interest}

We declare that we have no financial and personal relationships with other people or organizations that can inappropriately influence our work, and there is no professional or other personal interest of any nature or kind in any product presented in the manuscript entitled "Effective removal of cadmium ion from a simulated gastrointestinal fluid by Lentinus edodes". This article does not involve any studies with human or animal subjects. 


\section{References}

1. Aravindhan, R.; Madhan, B.; Rao, J.R.; Nair, B.U.; Ramasami, T. Bioaccumulation of chromium from tannery wastewater: An approach for chrome recovery and reuse. Environ. Sci. Technol. 2004, 38, 300-306.

2. Sabolic, I. Common mechanisms in nephropathy induced by toxic metals. Nephron Physiol. 2006, 104, 107-114.

3. Barbier, O.; Jacquillet, G.; Tauc, M.; Cougnon, M.; Poujeol, P. Effect of heavy metals on, and handling by, the kidney. Nephron Physiol. 2005, 99, 105-110.

4. Foulkes, E.C. Transport of toxic heavy metals across cell membranes. Proc. Soc. Exp. Biol. Med. 2000, 223, 234-240.

5. Chen, M.; Xie, J.; Zhao, G. Comparative effects of five chelating agents on testicular toxicity in mice induced by acute exposure to cadmium. Toxicol. Environ. Chem. 2006, 88, 325-330.

6. Al-Saadi, A.A.; Saleh, T.A.; Gupta, V.K. Spectroscopic and computational evaluation of cadmium adsorption using activated carbon produced from rubber tires. J. Mol. Liq. 2013, 188, 136-142.

7. Shahid, M.; Austruy, A.; Echevarria, G.; Arshad, M.; Sanaullah, M.; Aslam, M.; Nadee, M.; Nasim, W.; Dumat, C. EDTA-enhanced phytoremediation of heavy metals: A review. Soil Sediment Contam. 2014, 23, 389-416.

8. Custos, J.M.; Moyne, C.; Treillon, T.; Sterckeman, T. Contribution of Cd-EDTA complexes to cadmium uptake by maize: A modelling approach. Plant Soil 2014, 374, 497-512.

9. George, G.N.; Prince, R.C.; Gailer, J.; Buttigieg, G.A.; Denton, M.B.; Harris, H.H.; Pickering, I.J. Mercury binding to the chelation therapy agents DMSA and DMPS and the rational design of custom chelators for mercury. Chem. Res. Toxicol. 2004, 17, 999-1006.

10. Wang, C.; Fang, Y.; Peng, S.; Ma, D.; Zhao, J. Synthesis of novel chelating agents and their effect on cadmium decorporation. Chem. Res. Toxicol. 1999, 12, 331-334.

11. Idouraine, A.; Khan, M.J.; Weber, C.W. In vitro mineral binding capacity of three fiber sources for $\mathrm{Ca}, \mathrm{Mg}, \mathrm{Cu}$ and $\mathrm{Zn}$ by two different methods. Int. J. Food Sci. Nutr. 1996, 47, 285-293.

12. Chen, G.; Zeng, G.; Tang, L.; Du, C.Y.; Jiang, X.Y.; Huang, G.H.; Liu, H.L.; Shen, G.L. Cadmium removal from simulated wastewater to biomass byproduct of Lentinus edodes. Bioresour. Technol. 2008, 99, 7034-7040.

13. Zheng, R.; Jie, S.; Hanchuan, D.; Moucheng, W. Characterization and immunomodulating activities of polysaccharide from Lentinus edodes. Int. Immunopharmacol. 2005, 5, 811-820.

14. Costantino, H.R.; Griebenow, K.; Langer, R.; Klibanov, A.M. On the pH memory of lyophilized compounds containing protein functional groups. Biotechnol. Bioengin. 1997, 53, 345-348.

15. Siao, F.Y.; Lu, J.F.; Wang, J.S.; Inbaraj, B.S.; Chen, B.H. In vitro binding of heavy metals by an edible biopolymer poly( $\gamma$-glutamic acid). J. Agric. Food Chem. 2009, 57, 777-784.

16. $\mathrm{Ou}, \mathrm{S}$; Gao, K.; Li, Y. An in vitro study of wheat bran binding capacity for $\mathrm{Hg}, \mathrm{Cd}$ and $\mathrm{Pb}$. J. Agric. Food Chem. 1999, 47, 4714-4717.

17. Oberleas, D.; Muhrer, M.E.; O’Dell, B.L. Dietary metal-complexing agents and zinc availability in the rat. J. Nutr. 1966, 90, 56-62. 
18. Ghimire, K.N.; Inoue, K.; Yamaguchi, H.; Makino, K.; Miyajima, T. Adsorptive separation of arsenate and arsenite anions from aqueous medium by using orange waste. Water Res. 2003, 37, 4945-4953.

19. Gupta, V.K.; Sharma, S. Removal of cadmium and zinc from aqueous solutions using red mud. Environ. Sci. Technol. 2002, 36, 3612-3617.

20. Herrero, R.; Cordero, B.; Lodeiro, P.; Rey-Castro, C.; de Vicente, M.E.S. Interactions of cadmium(II) and protons with dead biomass of marine algae Fucus. sp. Mar. Chem. 2006, 99, 106-116.

21. Say, R.; Yilmaz, N.; Denizli, A. Biosorption of cadmium, lead, mercury, and arsenic ions by the fungus Penicilliumpur purogenum. Sep. Sci. Technol. 2003, 38, 2039-2053.

22. Mohanty, K.; Jha, M.; Meikap, B.C.; Biswas, M.N. Biosorption of Cr (VI) from aqueous solutions by Eichhornia crassipes. Chem. Eng. J. 2006, 117, 71-77.

23. Vigneshwaran, N.; Ashtaputre, N.M.; Varadarajan, P.V.; Nachane, R.P.; Paralikar, K.M.; Balasubramanya, R.H. Biological synthesis of silver nanoparticles using the fungus Aspergillus flavus. Mater. Lett. 2007, 61, 1413-1418.

24. Yalcin, S. The mechanism of heavy metal biosorption on green marine Macroalga Enteromorpha linza. CLEAN-Soil Air Water 2014, 42, 251-259.

25. Davis, T.A.; Volesky, B.; Mucci, A. A review of the biochemistry of heavy metal biosorption by brown algae. Water Res. 2003, 37, 4311-4330.

26. Kaushik, G.; Thakur, I.S. Adsorption of colored pollutants from distillery spent wash by native and treated fungus: Neurospora intermedia. Environ. Sci. Pollut. Res. 2013, 20, 1070-1078.

27. Lim, A.P.; Aris, A.Z. A novel approach for the adsorption of cadmium ions in aqueous solution by dead calcareous skeletons. Desalin. Water Treat. 2014, 52, 3169-3177.

(C) 2014 by the authors; licensee MDPI, Basel, Switzerland. This article is an open access article distributed under the terms and conditions of the Creative Commons Attribution license (http://creativecommons.org/licenses/by/4.0/). 